\title{
Correlation between the shear-speed structure and thickness of the mantle transition zone
}

\author{
Sergei Lebedev ${ }^{\mathrm{a}, *}$, Sébastien Chevrot $^{\mathrm{b}}$, R.D. van der Hilst ${ }^{\mathrm{c}}$ \\ a MIT, EAPS, Room 54-512, Cambridge, MA 02139, USA \\ ${ }^{\mathrm{b}}$ Observatoire Midi Pyrénées, 14 Avenue Edouard Belin, 31400 Toulouse, France \\ ${ }^{\mathrm{c}}$ MIT, EAPS, Room 54-514, Cambridge, MA 02139, USA
}

Received 28 October 2001; received in revised form 27 June 2002; accepted 23 July 2002

\begin{abstract}
The 410 and $660 \mathrm{~km}$ seismic discontinuities that bound the mantle transition zone (TZ) are attributed to phase transformations in olivine structure. This implies that variations in TZ thickness $\left(H_{\mathrm{TZ}}\right)$ should correlate with those in $\mathrm{TZ}$ temperature. Pertinent seismic evidence has so far been ambiguous, however. We measure converted-wave $(P \mathrm{~d} s)$ differential times $t_{\mathrm{diff}}=$ $t_{P 660 s}-t_{P 410 s}$ in SE Asia and Australia and compare them with $S$-velocity $\left(\beta_{\mathrm{TZ}}\right)$ estimates from regional tomographic models. Both $t_{\mathrm{diff}}$ and $\beta_{\mathrm{TZ}}$ vary on a scale of a few hundred kilometers. Inferred variations in $H_{\mathrm{TZ}}$ are up to $\pm 30 \mathrm{~km}$ over length scales larger than $500 \mathrm{~km}$, implying $\pm 200 \mathrm{~K}$ thermal heterogeneity if the effect of composition can be neglected. $t_{\text {diff }}$ and $\beta_{\mathrm{TZ}}$ correlate strongly; the linear dependence of $H_{\mathrm{TZ}}$ on the average temperature within the TZ is consistent with olivine Clapeyron slopes. We also show that this relationship holds on a global-scale as well, provided that the scalelengths and uncertainties of the variations in $t_{\mathrm{diff}}$ and $\beta_{\mathrm{TZ}}$ are taken into account. These results confirm that the transformations in olivine structure give rise to the 410 and $660 \mathrm{~km}$ discontinuities globally.
\end{abstract}

(c) 2003 Elsevier Science B.V. All rights reserved.

Keywords: Discontinuities; Converted waves; Receiver functions; Tomography; Clapeyron slopes; Olivine

\section{Introduction}

Accurate constraints on the properties of the transition zone discontinuities are necessary for the understanding of the patterns of the mantle flow as well as the very composition of the mantle. Owing to observational difficulties, current models are characterized by large uncertainties, and even their basic features are debated (e.g. Irifune et al., 1998; Shim et al., 2001).

* Corresponding author. Fax: +1-617-258-9697. E-mail addresses: sergei@quake.mit.edu (S. Lebedev), Sebastien.Chevrot@cnes.fr (S. Chevrot), hilst@mit.edu (R.D. van der Hilst).
The mantle transition zone (TZ) is bounded by two sharp seismic discontinuities at approximately 410 and $660 \mathrm{~km}$ depth. According to the most commonly accepted view (Fig. 1) the discontinuities (410 and 660) are due to phase transformations in olivine, in an olivine-dominated mantle. For a typical mantle adiabat, the olivine-wadsleyite transition $(\alpha \rightarrow \beta)$ occurs at pressures corresponding to $410 \mathrm{~km}$ depth and it is thought to be the cause of the jump in the elastic properties of the mantle rock observed at the depth. The break-down of the spinel phase (ringwoodite) into perovskite and magnesiowüstite $(\mathrm{sp} \rightarrow \mathrm{pv}+\mathrm{mw}$, also referred to as the post-spinel transformation) has been observed at conditions that occur near $660 \mathrm{~km}$ depth in the mantle and is thought to be the cause of 


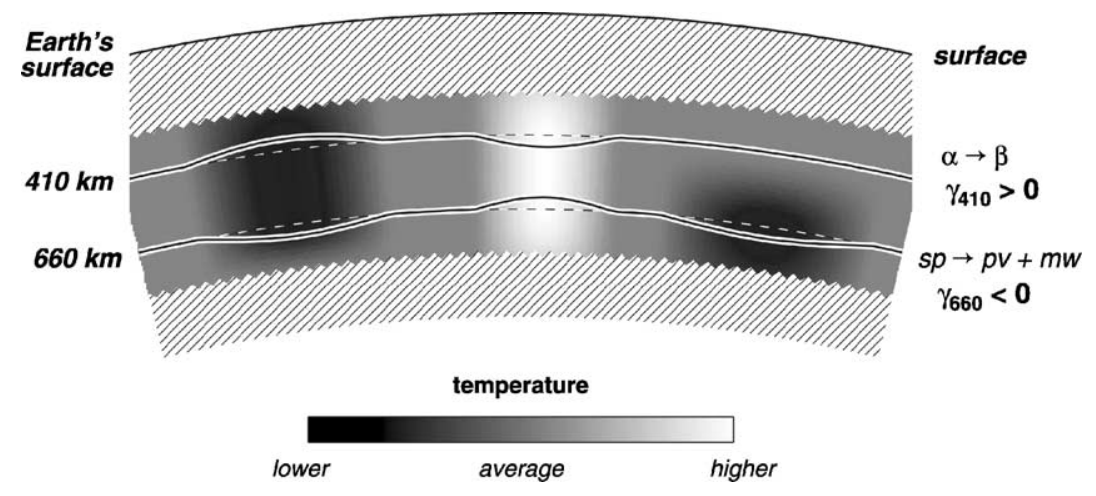

Fig. 1. Schematic depiction of the transition zone in an olivine-dominant mantle. Low temperatures cause a thickening of the transition zone; high temperatures - a thinning.

the 660 (Bernal, 1936; Anderson, 1967; Ringwood, 1969).

An important characteristic of a phase transformation is its Clapeyron slope $\gamma$, which is the temperature derivative of the pressure at which the transformation occurs $(\gamma=\mathrm{d} P / \mathrm{d} T)$. In the Earth, changes of the pressure of the transition will translate into changes of its depth, so that lateral variations in temperature can create topography on the seismic discontinuity. The Clapeyron slope of the $\alpha \rightarrow \beta$ transformation is positive (Suito, 1977; Katsura and Ito, 1989), so that a low-temperature anomaly will cause a local uplift of the $410 \mathrm{~km}$ discontinuity, whereas a high-temperature anomaly will cause a depression. The slope of the $\mathrm{sp} \rightarrow \mathrm{pv}+\mathrm{mw}$ transformation is probably negative (Navrotsky, 1980; Ito and Takahashi, 1989), implying a depression of the $660 \mathrm{~km}$ discontinuity in a low-temperature environment and an uplift at high temperatures.

This view is supported by mineralogical and seismological observations (e.g. Ito and Takahashi, 1989; Katsura and Ito, 1989; Bina and Helffrich, 1994; Weidner and Wang, 2000; Helffrich, 2000; Shearer, 2000), which, despite their rather large uncertainties are often taken for granted. The origin and properties of the discontinuities, however, are still enigmatic, owing to the difficulty in making the pertinent seismic and mineralogical measurements.

Phase transformations in the Earth occur over finite depth intervals in which multiple phases coexist, so that Clapeyron slopes at 410 or 660 cannot be defined thermodynamically (Bina and Helffrich,
1994). Finite-frequency seismic waves, however, see the discontinuities as sharp interfaces. By using seismic measurements of the depths to these apparent interfaces, one could constrain "effective" Clapeyron slopes at the discontinuities. Bina and Helffrich (1994) refer to them as "seismic" Clapeyron slopes and note that, except for a slight dependence on the seismic-wave frequency, they otherwise depend only on thermodynamic properties. By using seismic observables sensitive to pressure and temperature at the discontinuities and neglecting, as an initial assumption, possible effects of compositional heterogeneity on these observables, one could constrain the effective Clapeyron slopes.

Arrival times of seismic waves converted or reflected at 410 or 660 depend on (and can be used to constrain) lateral variations in the depth to the discontinuities (or the pressure of the corresponding phase transformation). The values of seismic velocities in the $\mathrm{TZ}$ can be used to infer temperature variations, with conversion factors from experimental and theoretical mineral physics. The effective Clapeyron slopes can thus be constrained with these two types of data.

Unfortunately, both types of seismic measurement are difficult to make in practice and, moreover, are not independent. Although many tomographic models map seismic heterogeneity in the TZ, the wavespeed values are uncertain (e.g. Becker and Boschi, 2002). Topography on the discontinuities have been measured using different approaches, often with conflicting results (see Shearer, 2000 and Helffrich, 2000 for 
reviews). Most previous studies have relied on crude estimates of the upper-mantle seismic-velocity structure in order to convert the arrival time of a pertinent seismic phase into the depth to a discontinuity. In addition, the topography and seismic heterogeneity are often measured with different lateral resolution which can distort or conceal existing correlation patterns.

In this study, we use the results of recent highresolution tomographic studies of SE Asia and Australia and combine them with measurements of the converted-wave $(P \mathrm{~d} s)$ delay times. The tomographic models were computed using large waveform data sets with substantial resolving power in the transition zone. We do not, however, take the tomographically derived $S$-velocities at face value, but instead perform extensive testing and derive robust estimates of the $S$-velocity values and their uncertainties in the TZ beneath the stations of the $P \mathrm{~d} s$ dataset. The tomography and $P \mathrm{~d} s$ analysis both achieve a lateral resolution in the TZ of about $500-600 \mathrm{~km}$. Subsequently, we attempt to extend our analysis to global-scale using published global tomographic models.

\section{Previous studies: approaches and results}

\subsection{Short-period, near-source phases}

The analysis of short-period waves generated from deep subduction-zone earthquakes and reflected or converted from discontinuities near the source (e.g. Vidale and Benz, 1992; Wicks and Richards, 1993; Collier and Helffrich, 1997; Castle and Creager, 1998) has a number of advantages. First, it offers a high lateral resolution (resolution length of $100 \mathrm{~km}$ or less). Second, the temperature in subducting slabs can be estimated roughly from the age and descent rate of the cold oceanic lithosphere. Both local uplift of 410 and depression of 660 have been observed, with their magnitude generally consistent with the olivine-transformation origin of the discontinuities. Subduction zones, however, represent a small fraction of the upper-mantle, characterized by extremely large temperature anomalies, and it is not certain to what extent the properties of the discontinuities in these regions are representative of those elsewhere in the Earth.

\subsection{Long-period reflections}

The best global coverage has been achieved in the studies using underside reflections of long-period shear waves (e.g. Gössler and Kind, 1996; Flanagan and Shearer, 1998; Gu et al., 1998). However, the data sampling is achieved at the expense of lateral resolution, which is often difficult to quantify. $S c S$ reverberations (e.g. Revenaugh and Jordan, 1991) have been used in regional-scale studies. Absolute discontinuity depths are determined from differential travel times between reflected phases and a reference phase (e.g. SS) using rays traced in seismic models of the crust and upper-mantle in the region of the reflection points. Because uncertainties in the models of the highly heterogeneous upper-mantle can translate into substantial errors of the inferred discontinuity topography, the thickness of the $\mathrm{TZ}\left(H_{\mathrm{TZ}}\right)$ can be measured more accurately (using underside-reflection differential times) than the topography on either 410 or 660. Finally, long-period seismic phases used in the studies have broad and complex sensitivity volumes (e.g. Hung et al., 2000; Zhao et al., 2000). Ray-theoretical interpretation of the differential travel times can be significantly in error (Neele et al., 1997) for discontinuity topography on a scale of a few hundred kilometers (such as in subduction zones). Chaljub and Tarantola (1997) suggested that uplifts and depressions of the 660 can be retrieved correctly from $t_{S S}$ to $t_{S 660 S}$ delays only at length scales larger than 1500 and $3000 \mathrm{~km}$, respectively. Shearer et al. (1999) argued that if the data coverage is dense and sufficient lateral averaging is applied, the presence of small-scale topography does not cause a significant bias in the maps of large-scale discontinuity topography and $\mathrm{TZ}$ thickness variations.

The correlation of global maps of $H_{\mathrm{TZ}}$ obtained using $S S$ precursors with tomographic $\mathrm{TZ}$ wavespeeds is roughly consistent with the olivine Clapeyron slopes (Flanagan and Shearer, 1998) but is unexpectedly low.

\subsection{Short-period near-receiver conversions}

In contrast to the long-period underside reflections, short-period $P$-to- $S$ conversions on the receiver side offer lateral resolution of a few hundred kilometers. With this technique, data coverage directly reflects the distribution of broad band stations (e.g. Bostock, 
1996; Dueker and Sheehan, 1997; Gurrola and Minster, 1998; Li et al., 2000) and is best in continental regions, in particular, Eurasia and North America. Sampling of oceanic mantle has been poor, but this should be improved with ocean-bottom seismometer deployments.

Chevrot et al. (1999) performed a global-scale study of $P \mathrm{~d} s$ travel times, supplementing new measurements with those from earlier studies. Their analysis showed that variations in the absolute $P 410 s$ and $P 660$ s arrival times are dominated by the impact of seismic heterogeneity above 410 and that the discontinuity topography has only a second-order effect. To determine the absolute depth to a discontinuity from the converted-phase arrival times it is necessary to have a very accurate tomographic model of the upper-mantle for both $P$ and $S$ velocities. The differential travel times $t_{\text {diff }}=t_{P 660 s}-t_{P 410 s}$, however, are not sensitive to the structure above 410 and can be used to constrain the TZ thickness.

The comparison of $t_{\text {diff }}$ with the seismic velocities in the TZ taken from global tomographic models ( $\mathrm{Su}$ et al., 1994; Grand et al., 1997; Van der Hilst et al., 1997) showed poor correlation (Chevrot et al., 1999), a surprising result because the olivine-transformation model predicts strong effects of temperature on both the velocities and discontinuity topography (Fig. 1). Here we suggest that the discrepancy is mostly due to differences in spatial resolution as well as uncertainties of the data compared.

\section{Converted-wave analysis}

$P \mathrm{~d} s$ phases are the arrivals of the waves converted from $P$ to $S$ at a discontinuity at depth $d$, in this study either 410 or $660 \mathrm{~km}$ (Fig. 2). Our analysis is based on the approach first introduced by Vinnik (1977). For the data processing we follow Chevrot et al. (1999).

\section{1. $t_{P 410 s}$ and $t_{P 660 s}$ measurements}

For each station, we collect all available traces and-in an initial visual selection-reject those with strong background noise before the $P$ onset. Each three-component seismogram is then transformed into a series of "bumps" by means of rotation and deconvolution by the principal component of the recorded

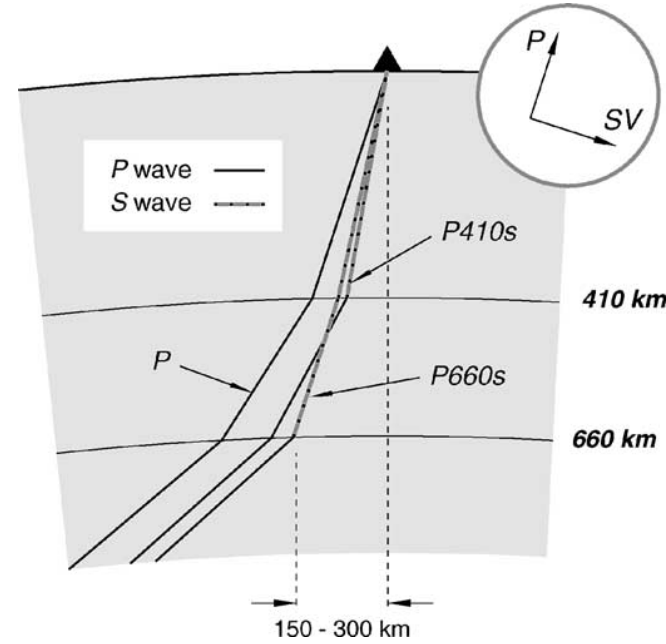

Fig. 2. Schematic ray diagram of the $P, P 410 s$, and $P 660 s$ phases. The triangle denotes a seismic station on the Earth's surface. The axes $P$ and $S V$ (top right) are in the direction of the $P$ and $S V$ waves particle motion.

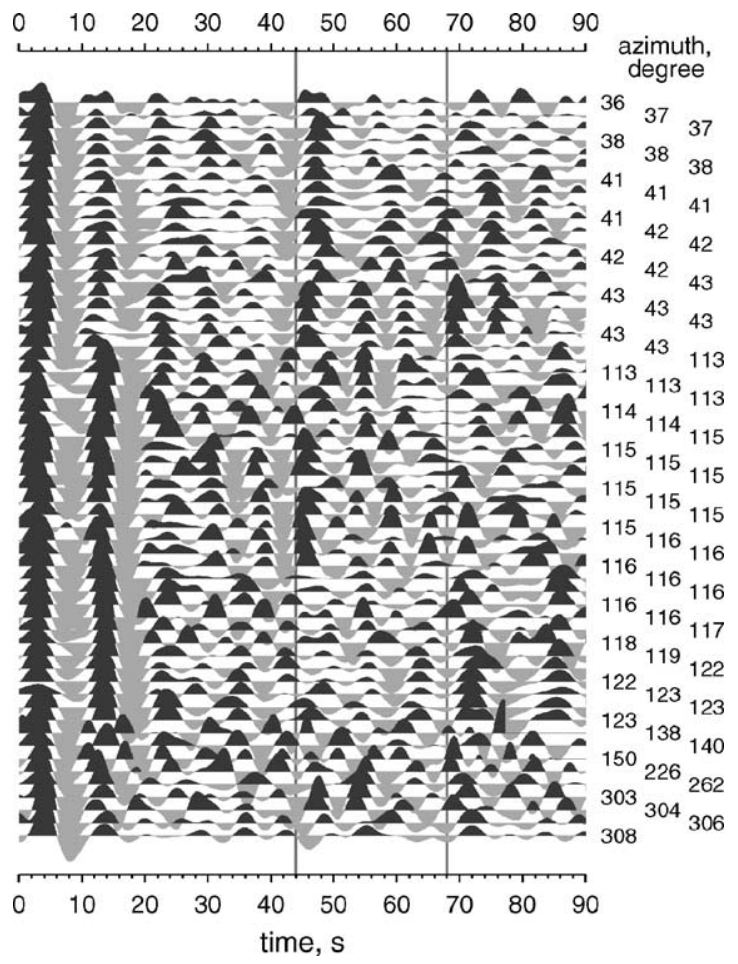

Fig. 3. Fifty-eight processed traces at the station QIZ, low-pass filtered at $8 \mathrm{~s}$ and ordered by azimuth. The global-average arrival times of $P 410$ s and $P 660$ s are shown with vertical lines, at 44 and $68 \mathrm{~s}$, respectively. 
$P$-wave train, with a move-out correction depending on the slowness of the $P$-wave. Traces with a prominent phase (e.g. $P c P$ or $P P$ ) in the coda of the $P$-wave and those with the $S V$-component amplitude exceeding an empirical threshold of $15 \%$ of the $P$-wave amplitude are discarded. Usually, the $P \mathrm{~d} s$ phases are not clearly visible on all individual traces (Fig. 3). The arrival times $t_{P 410 s}$ and $t_{P 660 s}$ are measured on the stacks of all traces (Fig. 4), relative to the arrival of the $P$-wave, with measurement errors determined using bootstrap analysis (Efron and Tibshirani, 1991).
In addition to low signal-to-noise ratios (typically, at ocean-island and portable stations), reasons for data rejection include complexity of the traces due to strong upper-mantle heterogeneity or small-scale topography on the discontinuities (e.g. in active subduction zones), and insufficient numbers of available records for a meaningful error analysis (temporary or recently installed stations).

Since we stack the records produced by events at different azimuths and distances, the piercing points of the waves at the discontinuities are distributed over an
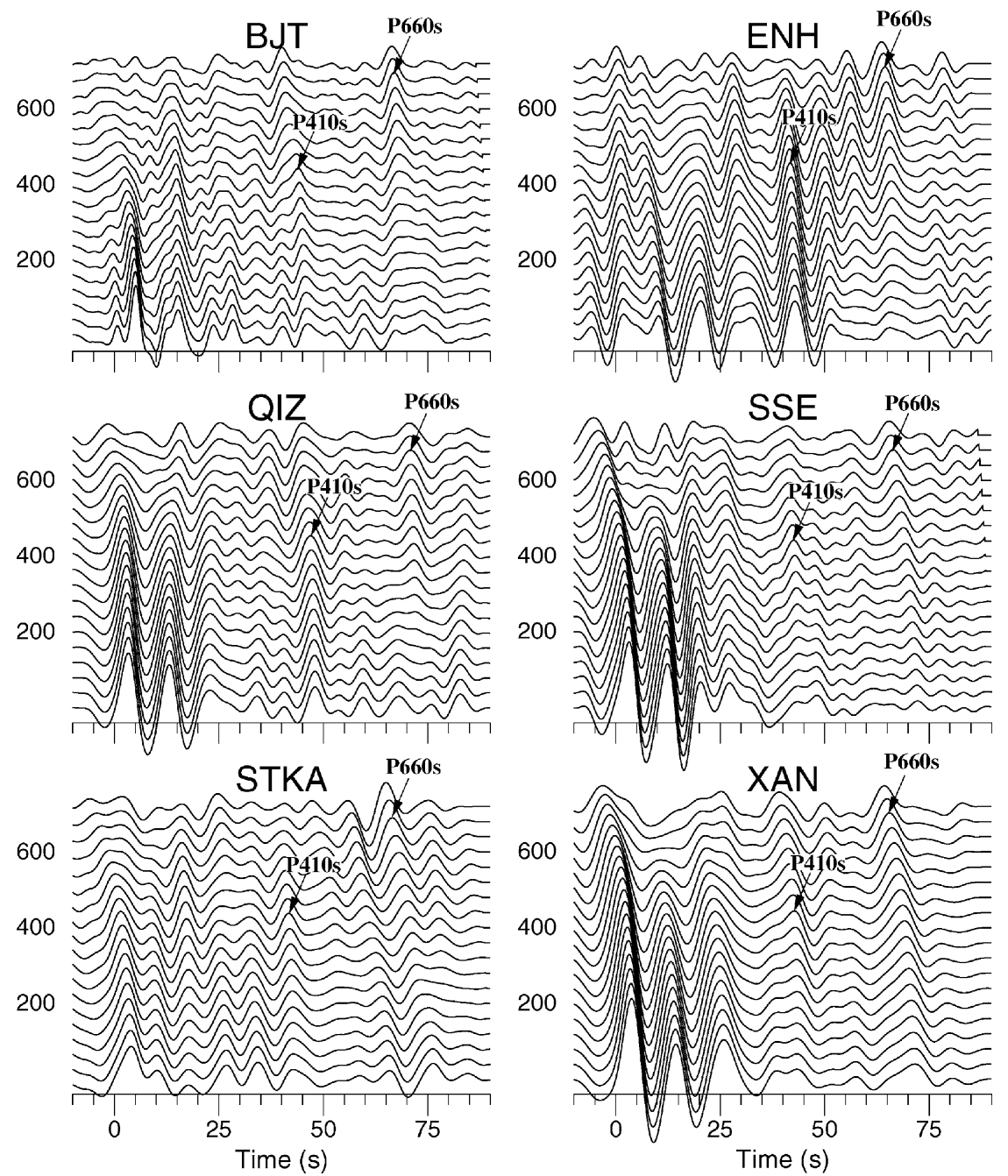

Fig. 4. Depth stacks at six stations. The vertical-scale is depth $(\mathrm{km})$. The time of the converted-phase arrival corresponds to the top of its bump and is measured relative to $P(0 \mathrm{~s})$. All traces in our dataset are low-passed at $6 \mathrm{~s}$, except for those from the stations QIZ and STKA (8s). 
area of finite width beneath the station (Fig. 2). Taking into account the $100-300 \mathrm{~km}$ width of the Fresnel zone of the waves at the the discontinuities (see Chevrot et al., 1999 for discussion), we estimate the lateral resolution of the measurements at around $500-600 \mathrm{~km}$.

\subsection{Differential times $t_{\mathrm{diff}}$}

Below the discontinuity $d$ (Fig. 2), the paths of the $P$ and $P \mathrm{~d} s$ waves are virtually identical to one another, and to first-order the relative arrival time $t_{P \mathrm{~d} s}$ depends only on the depth to the discontinuity $d$ and the $P$ - and $S$-velocity structure above it.

Our tomographic models represent $S$ but not $P$ velocities. In the absence of reliable constraints on $P$-wave speed we do not attempt to estimate the absolute values of the depths to the discontinuities $\left(d_{410}\right.$ and $\left.d_{660}\right)$. In principle, $P$-velocity anomalies $(\delta \alpha)$ can be estimated from $S$-velocity anomalies $(\delta \beta)$ if the ratio $R=\delta \ln \beta / \delta \ln \alpha=(\delta \beta / \beta) /(\delta \alpha / \alpha)$ is known. Unfortunately, applicability of this estimate is questionable in the upper $200-300 \mathrm{~km}$ of the mantle, where lateral variations in $R$ are expected to be strong (e.g. Goes et al., 2000). Since the shallow seismic structure has the largest contribution to the $t_{P 410 s}$ and $t_{P 660 s}$ variations, errors due to the assumption of constant $R$ could be comparable in magnitude to or exceed the actual lateral variations of $d_{410}$ and $d_{660}$.

Without measuring the absolute depths to 410 and 660 we can still obtain constraints on transition zone structure in the form of the differential times $t_{\text {diff }}=$ $t_{P 660 s}-t_{P 410 s}$. As evident from Fig. 2, the paths of $P 660$ s and $P 410$ s are essentially the same below $660 \mathrm{~km}$ and above $410 \mathrm{~km}$ so that $t_{\text {diff }}$ depends only on the thickness of the transition zone and seismic velocities in it. With this approach we have one constraint per station $\left(t_{\text {diff }}\right)$, but we can use only the stations with robust measurements of both $t_{P 410 s}$ and $t_{P 660 s}$.

Fig. 5 shows the stations in the region covered by the tomographic models at which both $t_{P 410 s}$ and $t_{P 660 s}$ were measured successfully, along with the rest of the stations in the area. The set of measurements (Table 1) contains no values from island-arc stations on the top of subduction zones, a result of strong upper-mantle heterogeneity and small-scale discontinuity topography (e.g. Castle and Creager, 1998). There are only a few data points from the numerous stations of the portable SKIPPY array (Van der Hilst
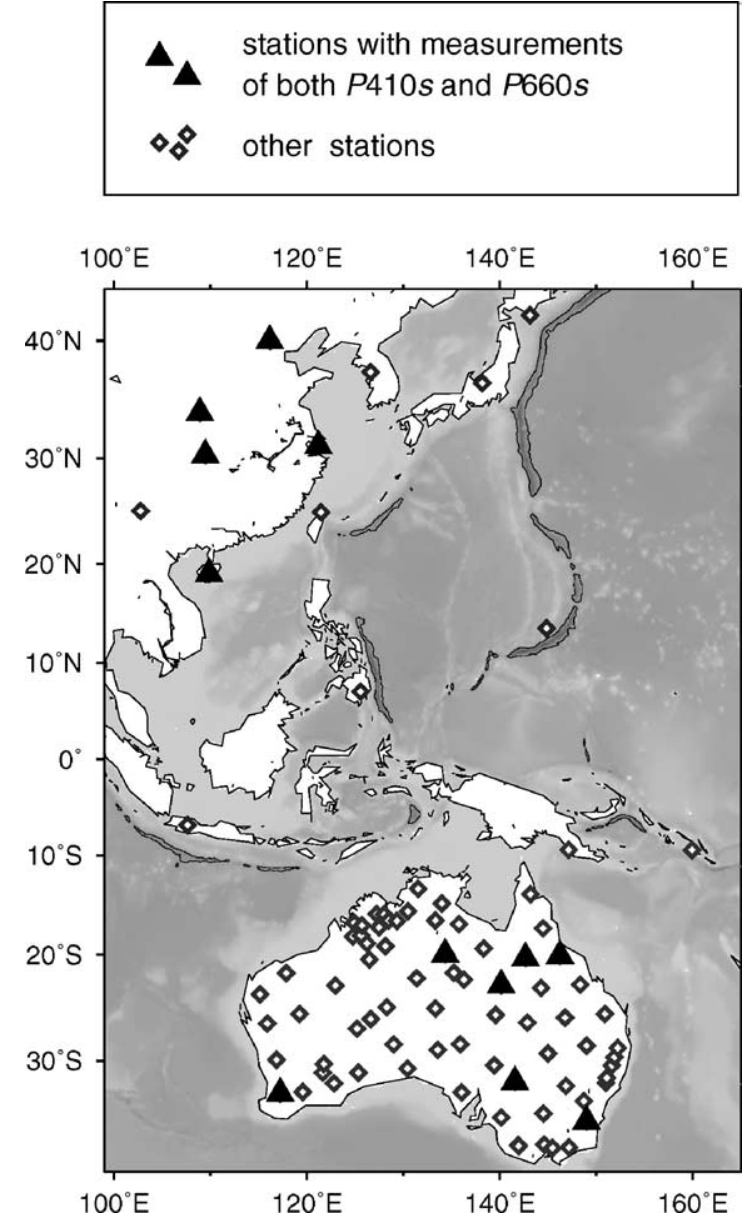

Fig. 5. Broadband stations in SE Asia and Australia.

et al., 1994) owing to the short time of instrument deployment at each location ( $\sim 5$ months) and relatively low signal-to-noise ratios at the periods considered here.

Important characteristics of the final set of measurements are that the values average laterally over $500-600 \mathrm{~km}$ and that the depths to the discontinuities do not change strongly within this range beneath the stations.

\section{Tomographic constraints}

Our upper-mantle, $S$-velocity models for SE Asia (Lebedev and Nolet, 2000) and Australia (Zielhuis and van der Hilst, 1996; Simons et al., 1999; Van 
Table 1

Travel times of the converted phases (seconds)

\begin{tabular}{|c|c|c|c|c|c|c|c|c|}
\hline No. & Station & Latitude & Longitude & $t_{P 410 s}$ & $t_{P 660 \mathrm{~s}}$ & $t_{\text {diff }}$ & $N_{\text {traces }}$ & Reference \\
\hline 1 & BJT & 40.02 & 116.17 & $45.6 \pm 0.2$ & $69.7 \pm 0.3$ & 24.1 & 82 & This study \\
\hline 2 & $\mathrm{CAN}$ & -35.32 & 149.00 & $45.0 \pm 0.4$ & $68.6 \pm 0.1$ & 23.6 & 135 & Chevrot et al. (1999) \\
\hline 3 & CTAO & -20.09 & 146.25 & $44.4 \pm 0.3$ & $69.2 \pm 0.2$ & 24.8 & 56 & Chevrot et al. (1999) \\
\hline 4 & ENH & 30.27 & 109.49 & $42.8 \pm 0.4$ & $67.2 \pm 0.6$ & 24.4 & 35 & This study \\
\hline 5 & NWAO & -32.93 & 117.23 & $44.0 \pm 0.5$ & $66.8 \pm 0.8$ & 22.8 & 55 & Chevrot et al. (1999) \\
\hline 6 & QIZ & 19.03 & 109.84 & $47.2 \pm 0.6$ & $70.4 \pm 0.5$ & 23.2 & 31 & This study \\
\hline 7 & SA03 & -20.34 & 142.67 & $44.4 \pm 0.5$ & $68.6 \pm 0.1$ & 24.2 & 13 & This study \\
\hline 8 & SA04 & -22.94 & 140.14 & $43.0 \pm 0.2$ & $66.5 \pm 0.5$ & 23.5 & 15 & This study \\
\hline 9 & SSE & 31.10 & 121.19 & $44.2 \pm 0.1$ & $68.8 \pm 0.4$ & 24.6 & 84 & This study \\
\hline 10 & STKA & -31.88 & 141.59 & $43.1 \pm 0.2$ & $68.7 \pm 0.6$ & 25.6 & 14 & This study \\
\hline 11 & WRAB & -19.93 & 134.36 & $42.6 \pm 0.3$ & $66.0 \pm 0.3$ & 23.4 & 58 & Chevrot et al. (1999) \\
\hline 12 & XAN & 34.03 & 108.92 & $44.4 \pm 0.3$ & $68.8 \pm 0.2$ & 24.4 & 54 & This study \\
\hline
\end{tabular}

The arrival times (relative to the $P$-wave) of the $P \mathrm{~d} s$ phases converted at 410 and $660\left(t_{P 410 s}\right.$ and $\left.t_{P 660 s}\right)$ are followed by the differential travel time $t_{\mathrm{diff}}=t_{P 660 s}-t_{P 410 s}$, the number of stacked records, and the source of the data. Crustal corrections are applied to $t_{P 410 s}$ and $t_{P 660 s}$, as in Chevrot et al. (1999); $t_{\text {diff }}$ does not depend on the corrections.

der Hilst et al., in preparation) were constrained by means of multimode inversions of large waveform datasets (4040 and 2250 seismograms, respectively) (Fig. 6). The waveforms contained long- and intermediate-period Rayleigh waves and regional $S$ and multiple $S$ waves and were inverted using the partitioned waveform inversion (Nolet, 1990; Zielhuis and van der Hilst, 1996) (Australia) and the automated partitioned waveform inversion (Lebedev and
Nolet, 2000) (SE Asia). Both tomographic studies achieve dense regional-path coverage of the target regions and provide $500-600 \mathrm{~km}$ lateral and $\sim 150 \mathrm{~km}$ vertical resolution in the TZ.

\subsection{Resolution}

The sampling with the waveform data used in the tomography is best in the upper $200 \mathrm{~km}$ of the mantle,

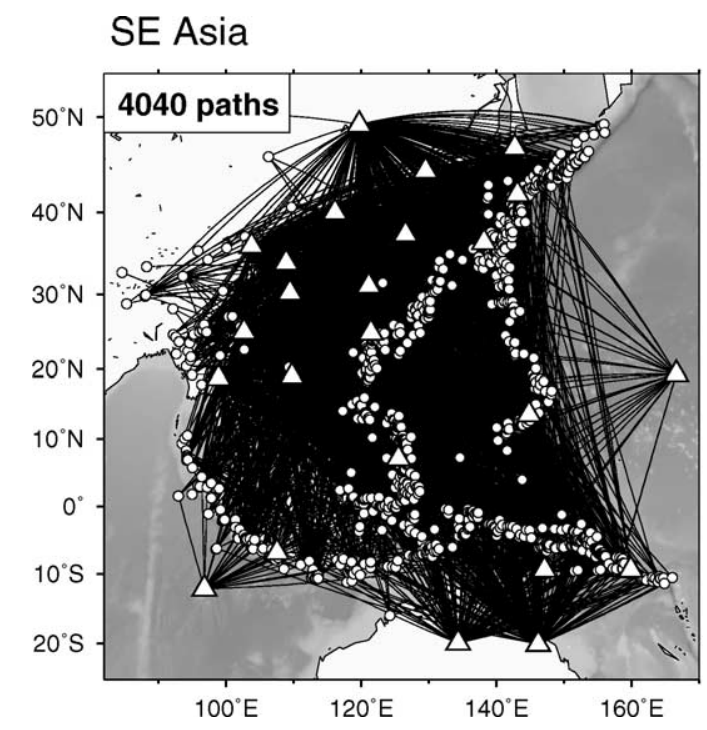

\section{Australia}

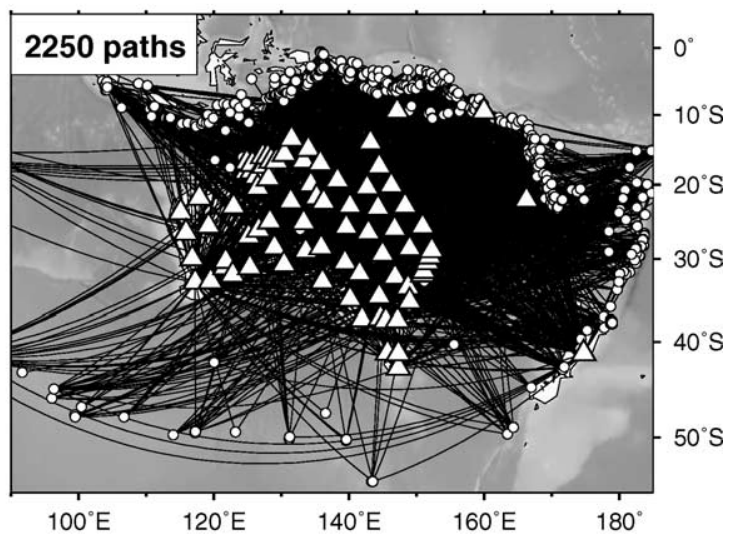

$\circ{ }_{0}^{\circ}$ sources $\Delta_{\triangle}$ stations

Fig. 6. Ray-path coverages used in the waveform tomography of SE Asia (Lebedev and Nolet, 2000) and Australia (Simons et al., 1999; Van der Hilst et al., in preparation). 
which is also the depth range of the highest lateral heterogeneity. Here, the lateral-resolution length is $300-400 \mathrm{~km}$. In a series of resolution tests, the upper 150,200 , and $300 \mathrm{~km}$ of the actual models were used as input patterns, with zero perturbations everywhere below. In the output of the inversions (damped and smoothed the same way as the actual data inversions) some of the more pronounced shallow anomalies were smeared down by about $100 \mathrm{~km}$, but no artificial deep structure appeared, which suggests that the structure observed in the transition zone is unlikely to contain artifacts due to shallower anomalies.

The data sampling of the transition zone is weaker than that in the upper layers but still adequate for our purposes. The estimated resolution length increases to about $500 \mathrm{~km}$, and anomaly magnitudes become underestimated due to damping (because the models are parameterized using regular grids and because damping parameters were chosen so that the anomalies with best data sampling were retrieved correctly, the anomalies with average sampling are overdamped). The bias, or the amount by which the magnitude is underestimated, varies spatially due to uneven data coverage and varying patterns of heterogeneity. In order to combine our converted-wave measurements with the seismic-velocity data we first attempt to correct for the magnitude bias and estimate the true $S$-velocity values in the upper and lower-transition-zone beneath each station of the $P \mathrm{~d} s$ dataset.

\subsection{Absolute $S$-velocity values}

A tomographic model can be regarded as the "true" model of the subsurface passed through a "resolution filter". The filter depends on data sampling, data quality, and the regularization of the inversion; it accounts for the differences between the tomographic model and the actual Earth structure. Ideally, we would like to find an "inverse" of the filter that would reproduce the true structure from the tomographic model.

The sensitivity volumes of long-period $S$ waves effectively average out the perturbations at shortest wavelengths. Accounting for this, regularization of tomographic inversions included smoothness constraints on the solutions. While trying to restore the true anomaly magnitudes, we can realistically aim at obtaining a smoothed model of the true Earth structure, such that at every point in the model the
$S$-velocity value is an accurate average over an area with a width of a few hundred kilometers (this width is the resolution length, similar to the averaging length of Backus and Gilbert, 1968). The $t_{\text {diff }}$ measurements average laterally over about $500 \mathrm{~km}$, a width similar to the resolution length of the tomography in the transition zone. We wish to obtain robust estimates of the $500 \mathrm{~km}$ lateral $S$-velocity averages beneath the stations.

For each of the two tomographic models, we look for an "inverse filter" in the form of a set of scaling factors, one per knot of the model grid. The magnitude bias can be corrected for by multiplying the values in the tomographic model with these scaling factors. We begin the iterative search for the factors by using the actual models as input patterns for resolution tests. The models that emerge in the output of the tests are generally similar to the input, the main difference being the reduced magnitude of anomalies, especially in the transition zone. Next, we use the input/output magnitude ratios to scale up the values in the input models. Repeating the tests, we observe that the output $S$ velocities are now closer to the ones in the actual models. This iterative procedure converges to the synthetic input models such that the output of the tests is very similar to the actual models obtained in the inversion of the data (Fig. 7).

These "best-fitting" synthetic models are our best estimate for the true upper-mantle structure beneath the regions. Further analysis, however, is needed to insure the robustness of the values beneath the stations of the $P \mathrm{~d} s$ dataset. One major problem is the non-uniqueness of the synthetic models: there are many other models that could produce a similarly good fit. Furthermore, in poorly sampled parts, such as west-Australian TZ, the tomographic solution is constrained weakly and may depend on heterogeneity elsewhere in the model. Instead of accepting the $S$ velocities in the "best-fitting" models as true ones, we now investigate the behavior of the scaling factors during the iterations. The general patterns of heterogeneity are similar in the input for each test, but the relative magnitude of anomalies at different locations changes from one test to another. At the stations in the western and central Australia these variations cause large fluctuations of the computed scaling factor as a function of the test input pattern. This indicates strong trade-offs between the values beneath the stations 
test: input pattern
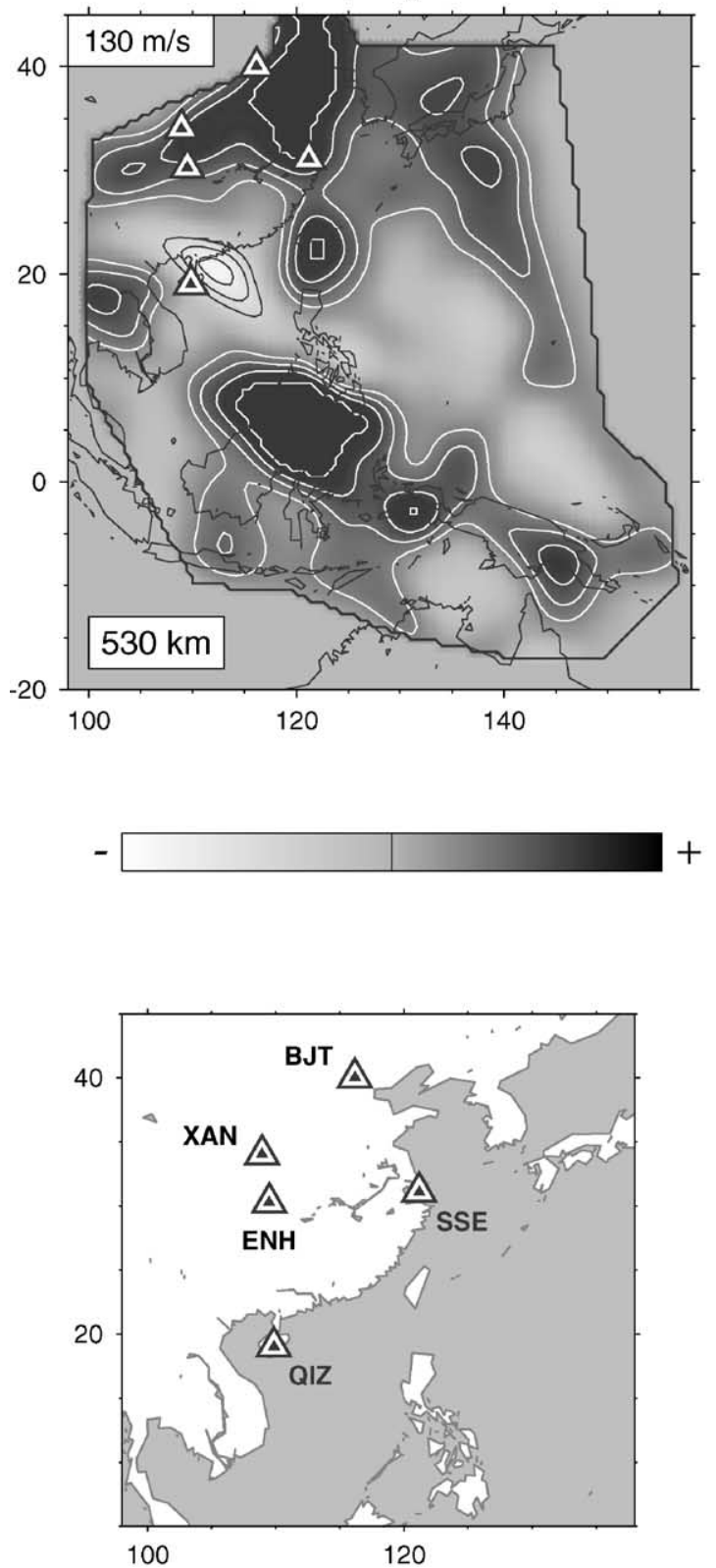

test: retrieved pattern

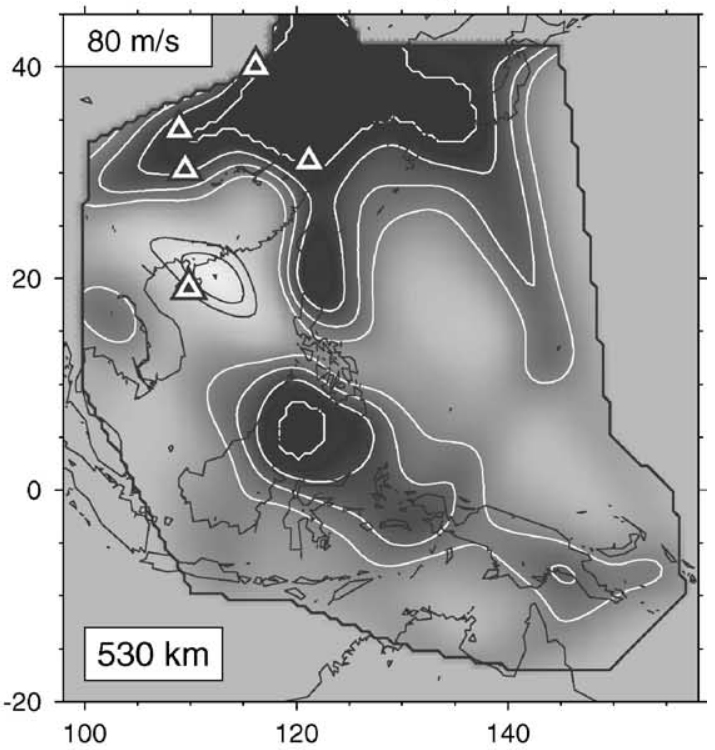

model

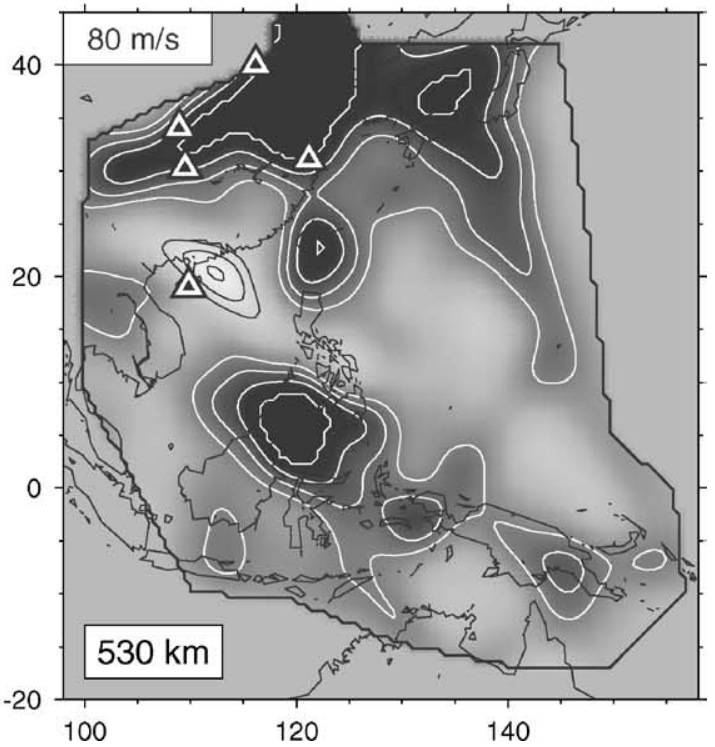

Fig. 7. An example of a resolution test for the SE Asian model. The input pattern (top left) is obtained from the actual model (bottom right) through scaling of the anomaly magnitudes, the scaling factor varying laterally. The output pattern of the test (top right) is similar to the actual model. Anomalies are plotted only in the well-sampled part of the region, bounded by the bold line. Gray-scale limits are shown in the top left corners of the frames. Stations of our data set are plotted as triangles, with the station names given on the map. 
and those elsewhere in the tomographic solution and means that scaling will not produce reliable estimates. For other stations, the factors are stable, their values ranging from $1.1 \pm 0.1$ to $3.3 \pm 0.7$.

Finally, we need to account for the fact that the a priori smoothness constraints on the Australian model were relatively weak, allowing structure with scale lengths down to $100-200 \mathrm{~km}$ to be present in the model. We filter out these small-scale variations using a posteriori smoothing. For each input and output model used in the iterations, a few smooth versions are computed, each with a smoothing function of a different half-width in the $300-800 \mathrm{~km}$ range. Small and monotonic change of the scaling factor with the smoothing width is another requirement for the Australian stations.

The requirements appeared to be severe quality criteria and were not met by all stations. Robust values for $S$ velocities in both the upper and lower-transitionzone were obtained for eight stations (Fig. 8). The values were recomputed relative to IASP91 (Kennett and Engdahl, 1991) for a reference period of $1 \mathrm{~s}$ (assuming $Q=143$ from PREM (Dziewonski and Anderson, 1981)). The upper-transition-zone anomaly $\left(\delta \beta_{410}\right)$ is an average over the $410-530 \mathrm{~km}$ depth range; the lower-transition-zone anomaly $\left(\delta \beta_{660}\right)$ is an average over the $540-660 \mathrm{~km}$ range. According to the standard deviations of the scaling factors, the uncertainties of $\delta \beta_{410}$ and $\delta \beta_{660}$ range from 2 to $32 \mathrm{~m} / \mathrm{s}$. We assign, however, larger, more conservative errors

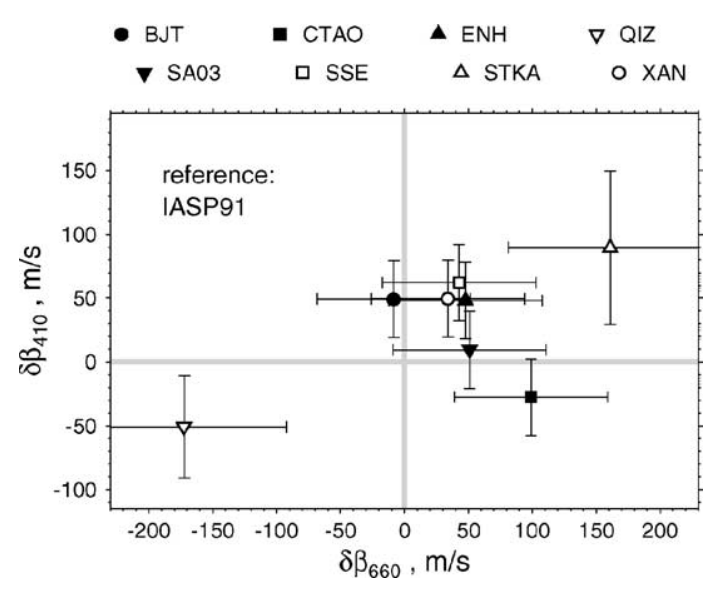

Fig. 8 . The $S$-velocity anomaly in the upper $\left(\delta \beta_{410}\right)$ and lower $\left(\delta \beta_{660}\right)$ transition zone beneath the eight stations of the dataset. of at least $30 \mathrm{~m} / \mathrm{s}$ to $\delta \beta_{410}$ and $40 \mathrm{~m} / \mathrm{s}$ to $\delta \beta_{660}$. The errors are assumed to be greater for the stations with greater scaling-factor variability (Fig. 8).

\section{Correlation of the transition zone thickness and seismic structure}

We begin the joint interpretation of our two datasets by superimposing the $\delta t_{\text {diff }}$ measurements on the tomographic images of the transition zone (Fig. 9). The $S$-velocity anomaly plotted at each point is "scaled" as described above and averaged vertically over the TZ depth range. $\delta t_{\text {diff }}$ values are plotted only for the eight stations with robust $S$-velocity estimates for the upper and lower TZ.

The eight points that pass all the quality tests show a good correlation between $t_{\text {diff }}$ and seismic-velocity. If the thickness of the transition zone were constant, then the differential-time $t_{\text {diff }}$ would be anomalously small in high-velocity regions and anomalously large in low-velocity ones. Since the observed pattern is the opposite, the thickness of the transition zone must vary and correlate positively with the seismic velocities.

We investigate the correlation quantitatively and in Fig. 10a plot the variations $\delta t_{\text {diff }}=t_{\text {diff }}-t_{\text {diff }}^{\text {iasp91 }}$ (where $t_{\text {diff }}^{\text {iasp91 }}=23.9 \mathrm{~s}$ ) against the transition zone anomalies $\delta \beta_{\mathrm{TZ}}$ corrected for the magnitude bias, $\delta \beta_{\mathrm{TZ}}=$ $\left(\delta \beta_{410}+\delta \beta_{660}\right) / 2$. The correlation coefficient is 0.94 .

The straight line through the points was determined using a bivariate regression. Even though this was not used as a constraint for the regression, the line goes through the origin of the coordinate system within the errors (the intercept is $0.1 \pm 0.4 \mathrm{~s}$ ). This is consistent with IASP91 being an accurate average model for the transition zone beneath SE Asia and Australia.

In Fig. $10 \mathrm{~b}$ we convert $\delta t_{\text {diff }}$ into the transition zone thickness anomaly $\delta H_{\mathrm{TZ}}$ (using the reference $\alpha$ and $\beta$ from IASP91, our $\delta \beta_{\mathrm{TZ}}$, and $\delta \ln \beta / \delta \ln \alpha=$ $1.7 \pm 0.7)$ and in Fig. 10c we convert $\delta \beta_{\mathrm{TZ}}$ into temperature variations $\delta T_{\mathrm{TZ}}$, assuming $\partial \ln \beta / \partial T=$ $-1.35 \times 10^{-4} \mathrm{~K}^{-1}$ from Karato (1993) and an uncertainty of the derivative of $0.4 \times 10^{-4} \mathrm{~K}^{-1}$. The temperature $\delta T_{\mathrm{TZ}}$ and thickness $\delta H_{\mathrm{TZ}}$ of the transition zone correlate strongly, with a correlation coefficient as high as 0.98. Furthermore, the slope of the straight line through our measurement points is $-0.13 \pm 0.07 \mathrm{~km} / \mathrm{K}$, consistent with $-0.13 \mathrm{~km} / \mathrm{K}$ 
SE Asia

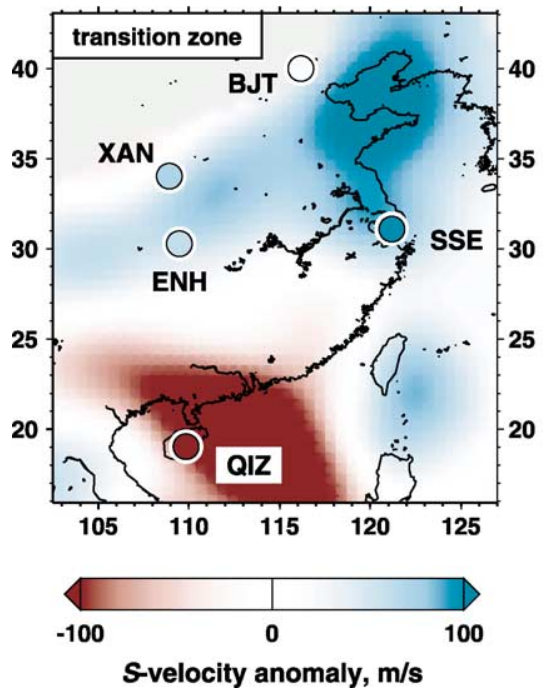

Australia

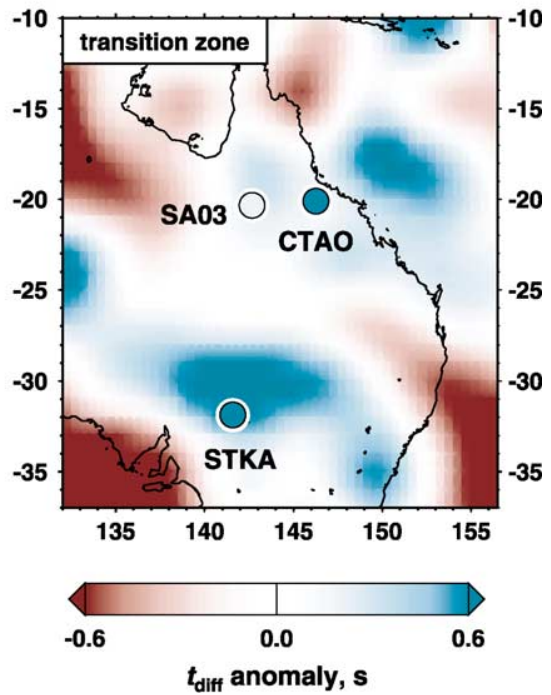

Fig. 9. Differential-time $\left(t_{\text {diff }}\right)$ measurements compared with $S$-velocity anomalies estimated (scaled) from the tomographic models (see text for explanation) and averaged over the transition zone depth range. Circles denote seismic stations, with color showing measured $t_{\text {diff }}$ anomaly. Reference $S$-velocity and $t_{\text {diff }}$ values are $5335 \mathrm{~m} / \mathrm{s}$ and $23.9 \mathrm{~s}$, respectively, computed from IASP91 (Kennett and Engdahl, 1991).
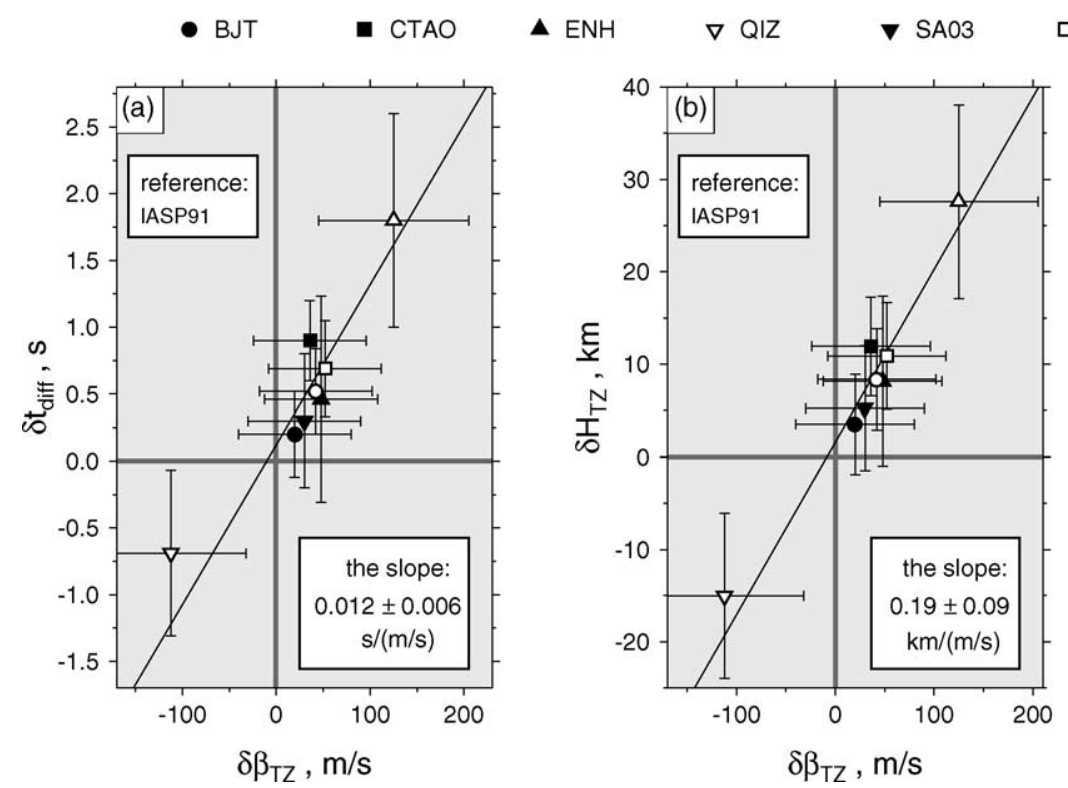

口 SSE $\triangle$ STKA O XAN

Fig. 10. Correlation between $S$-velocity in the transition zone $\left(\delta \beta_{\mathrm{TZ}}\right)$ and the differential-time $t_{\mathrm{diff}}$ (a), $\delta \beta_{\mathrm{TZ}}$ and the computed thickness of the transition zone $H_{\mathrm{TZ}}$ (b), and the estimated temperature in the transition zone $T_{\mathrm{TZ}}$ and the thickness $H_{\mathrm{TZ}}$ (c). Seismic-velocity anomalies $\delta \beta_{\mathrm{TZ}}$ are vertical averages over the transition zone depth range, and so are the estimated temperature anomalies $\delta T_{\mathrm{TZ}}$. 
computed assuming the Clapeyron slopes of the $\alpha \rightarrow$ $\beta$ and $\mathrm{sp} \rightarrow \mathrm{pv}+\mathrm{mw}$ transformations from Bina and Helffrich (1994) (2.9 and $-2.0 \mathrm{MPa} / \mathrm{K}$, respectively).

The strong correlation between $t_{\mathrm{diff}}$ and $\beta_{\mathrm{TZ}}$ (and thus between the TZ thickness and temperature) in SE Asia-Australia corroborates models in which phase transformations in olivine cause both 410 and 660 but appears to be at odds with the lack of correlation inferred from global models and datasets (Chevrot et al., 1999). We argue that this apparent inconsistency is due to differences in spatial resolution of $t_{\text {diff }}$ measurements on the one hand and of $\alpha_{\mathrm{TZ}}$ or $\beta_{\mathrm{TZ}}$ values from global tomography on the other. The resolution of global wavespeed heterogeneity in the TZ is most uniform at long wavelengths (Reference Earth Model Web Site: http://mahi.ucsd.edu/Gabi/rem.html; Becker and Boschi, 2002). However, the low (spherical harmonic) degree variations represent averages over distances (>2000-3000 km) that are much larger than the spatial averaging of the $t_{\text {diff }}$ measurements $(\approx 500 \mathrm{~km})$. This resolution difference will obscure the actual $t_{\text {diff }}-\beta_{\mathrm{TZ}}$ correlation if structural variations on a scale of a few hundred kilometers are present. In contrast, the $t_{\mathrm{diff}}$ and $\beta_{\mathrm{TZ}}$ measurements in Fig. 10a have similar lateral resolution so that the actual correlation can be measured.

We attempted to unscramble the global $t_{\text {diff }}-\beta_{\mathrm{TZ}}$ correlation using $77 t_{\text {diff }}$ measurements worldwide (from the dataset of Chevrot et al. (1999), complemented by the new data reported here) and $\beta_{\mathrm{TZ}}$ values beneath corresponding stations according to the 3D mantle model S16B30 (Masters et al., 1996) (this and other global models give mutually consistent results, as detailed below). Taken at face value, the datasets correlate weakly (Fig. 11a), with a correlation coefficient $r=0.28$. However, if we filter out shortwavelength variations of $t_{\text {diff }}$ (by replacing the values at individual stations with a weighted average of the values at all stations nearby) and low-pass filter the tomographic model (keeping only the largest-scale heterogeneity), the correlation increases dramatically (Fig. 11).

We compute the "smoothed" $t_{\text {diff }}$ values as $\sum_{i} w^{i} t_{\text {diff }}^{i} / \sum_{i} w^{i}$, with the weights $w^{i}=\cos ((\pi / 2)$ $\left.\left(d^{i} / L_{\delta t}\right)\right)$ for stations within a distance $d^{i}$ smaller than the chosen averaging length $L_{\delta t}$. The accuracy of the smoothing at a station depends on the presence of nearby stations. Geographically isolated stations have to be omitted, which we implement using a threshold value $w_{\min }$ : it is required that $\sum_{i} w^{i} \geq w_{\min }$.

As an alternative approach, we also expanded $t_{\text {diff }}$ variations into spherical harmonics using the singular value decomposition. The sparseness and especially the unevenness of the geographic distribution of the measurements resulted in large uncertainties $(30-100 \%)$ of the expansion coefficients, even at the lowest harmonic degrees. The spectral approach yields similar results, but because uneven data coverage is accounted for more easily in the spatial domain, we use the spatial-averaging (smoothing) scheme for the analysis.

Uneven distribution of the $t_{\text {diff }}$ measurement points may lead to "sampling artifacts" for certain values of $L_{\delta t}$ and $w_{\min }$. Also, our smoothing procedure introduces geographic correlation patterns into the $t_{\text {diff }}$ dataset; low-pass filtering of tomographic models also produces a geographic correlation in $\beta_{\mathrm{TZ}}$ values. Comparing one correlation coefficient to another may thus be meaningless. However, if we vary $L_{\delta t}$ and $w_{\min }$ values in wide ranges (we use 1000-10,000 km and $2-15$, respectively) and compute $r$ for every combination of $L_{\delta t}$ and $w_{\min }$, we can use the resulting range of $r$ as an indicator of $t_{\text {diff }}$-distribution correlation with a tomographic model.

From the result of our regional studies (Fig. 10) we had expected that the global correlation would

Fig. 11. Measurements of the differential-time anomaly $\delta t_{\text {diff }}$ at 77 stations around the world compared with the transition zone $S$-velocity anomaly $\delta \beta_{\mathrm{TZ}}$ according to the degree-16 tomographic model S16B30 (Masters et al., 1996). Circles denote seismic stations and are filled with color showing $t_{\text {diff }}$ anomaly. Left: $\delta t_{\text {diff }}$ measurements superimposed on the $550 \mathrm{~km}$ cross-sections through S16B30; right: $\delta t_{\text {diff }}$ measured at each station vs. $\delta \beta_{\mathrm{TZ}}$ beneath the station. Reference $t_{\mathrm{diff}}$ is $23.9 \mathrm{~s}$; reference $\beta_{\mathrm{TZ}}$ is the S16B30 average at $550 \mathrm{~km}$. (a) Unfiltered $\mathrm{S} 16 \mathrm{~B} 30$; original $\delta t_{\text {diff }}$ values. (b) S16B30 is unfiltered; $\delta t_{\text {diff }}$ distribution is smoothed laterally with $L_{\delta t}=2500 \mathrm{~km}$ and $w_{\text {min }}=1.5$; the smoothing could be done at 63 stations only (see text for explanation). (c) S16B30 is truncated at spherical-harmonic degree $l_{\max }=6$; $\delta t_{\text {diff }}$ distribution is smoothed with $L_{\delta t}=3000 \mathrm{~km}$ and $w_{\min }=2.5$ (60 stations). (d) S16B30 is truncated at $l_{\max }=2 ; \delta t_{\text {diff }}$ distribution is smoothed with $L_{\delta t}=5000 \mathrm{~km}$ and $w_{\min }=6$ (58 stations). 

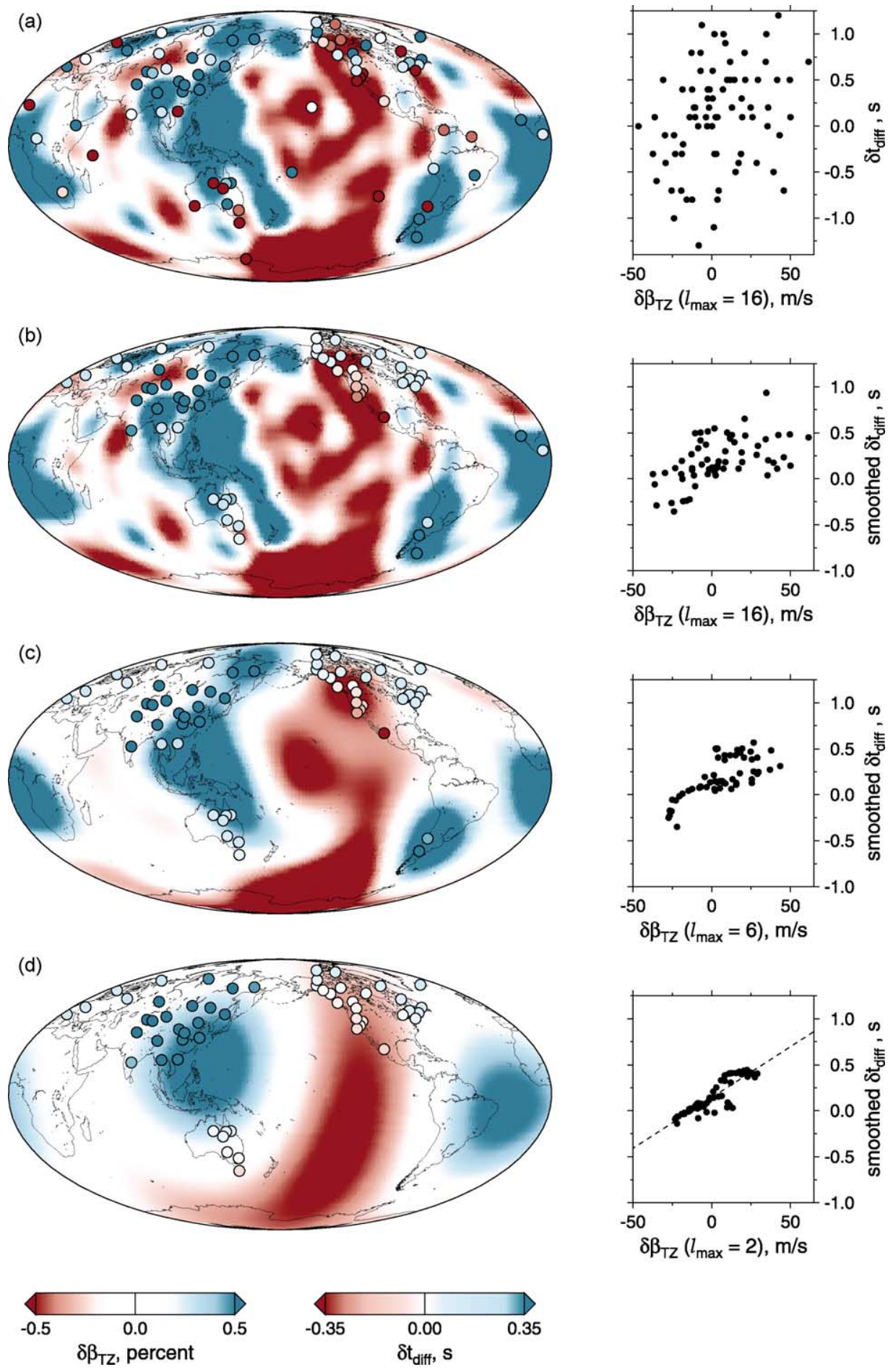
be better for the higher-degree (that is, shorterwavelength) mantle models. Surprisingly, we observe the opposite: $r$ generally decreases with increasing truncation degree $l_{\max }$ of the sphericalharmonic expansion of $\beta_{\mathrm{TZ}}$, from $0.8-1.0$ with $l_{\max }=2$ to $0.5-0.7$ with $l_{\max }=16$. Because the correlation between different global models exhibits a similar decrease with $l_{\max }$ (Reference Earth Model Web Site: http://mahi.ucsd.edu/Gabi/rem. html; Becker and Boschi, 2002), we attribute this trend to larger errors in $\beta_{\mathrm{TZ}}$ at higher degrees.

The correlation of smoothed $t_{\text {diff }}$ with other global models is similar at long wavelengths and decreases when the more uncertain shorter-wavelength $\beta_{\text {TZ }}$ variations are included. With the degree-12 model S12 ( $\mathrm{Su}$ et al., 1994) $r$ is in the 0.5-1.0 range; with the degree20 model S20A (Ekström and Dziewonski, 1998) $r=$ 0.4-0.6.

Comparing the "smoothed" $t_{\text {diff }}$ heterogeneity with the best-constrained, largest-scale $\beta_{\mathrm{TZ}}$ structure $\left(l_{\max }=2\right)$, we find that $t_{\text {diff }}$ and $\beta_{\mathrm{TZ}}$ correlate strongly (Fig. 11d). With assumed uncertainties of $0.3 \mathrm{~s}\left(t_{\text {diff }}\right)$ and $10 \mathrm{~m} / \mathrm{s}\left(\beta_{\mathrm{TZ}}\right)$, the slope of the line through the points is $0.011 \pm 0.003 \mathrm{~s}^{2} / \mathrm{m}$, consistent with the result for SE Asia-Australia in Fig. 10. Accurate uncertainty estimates for this global slope would be difficult to derive because the lateral variations of the errors in $\beta_{\mathrm{TZ}}$ are unknown and, more importantly, only a relatively small number of unevenly distributed $t_{\text {diff }}$ data points is available. Nevertheless, Fig. 11 confirms that the thickness of and seismic velocities within the transition zone correlate not only in SE Asia and Australia but elsewhere around the world as well.

\section{Discussion and conclusions}

The Clapeyron slopes of the $\alpha \rightarrow \beta$ and $\mathrm{sp} \rightarrow$ $\mathrm{pv}+\mathrm{mw}$ transformations, the two reactions that apparently give rise to the 410 and $660 \mathrm{~km}$ discontinuities, have opposite signs and similar absolute values: 2.9 and $-2.0 \mathrm{MPa} / \mathrm{K}$, respectively, according to Bina and Helffrich (1994). This implies that variations in $H_{\mathrm{TZ}}$ and $\beta_{\mathrm{TZ}}$ will correlate whether or not thermal heterogeneity within the $\mathrm{TZ}$ is vertically coherent, that is, even if the topography on 410 does not correlate with that on 660, as proposed by Gu et al. (1998) and Flanagan and Shearer (1998).
Because

$\delta H_{\mathrm{TZ}}=\delta d_{660}-\delta d_{410}$,

and, therefore,

$$
\begin{aligned}
\delta H_{\mathrm{TZ}}= & \gamma_{660}\left(\frac{\partial d}{\partial P}\right)_{660} \frac{\partial T}{\partial \ln \beta} \delta \ln \beta_{660} \\
& -\gamma_{410}\left(\frac{\partial d}{\partial P}\right)_{410} \frac{\partial T}{\partial \ln \beta} \delta \ln \beta_{410},
\end{aligned}
$$

with both the depth-pressure dependence $\partial d / \partial P$ and $\partial T / \partial \ln \beta$ similar at 410 and $660, \delta H_{\mathrm{TZ}}$ will correlate with $\left(\delta \beta_{410}+\delta \beta_{660}\right) / 2$. As long as seismic velocities do not oscillate in the transition zone depth range (the condition that $\left.\delta \beta_{\mathrm{TZ}} \approx\left(\delta \beta_{410}+\delta \beta_{660}\right) / 2\right)$, the values of $\delta H_{\mathrm{TZ}}$ and $\delta \beta_{\mathrm{TZ}}$ should correlate and plot approximately along the straight line on Fig. 10b. Deviations from this line would be likely to signal that anomalies of non-thermal origin (in either $\beta_{\mathrm{TZ}}$ or $H_{\mathrm{TZ}}$ ) are present in the location of the measurements and could provide insight into the mechanisms at work.

An effect of compositional transition zone heterogeneity on our observations cannot be ruled out. The values of "seismic" Clapeyron slopes may also be affected by the presence of nontransforming phases at the depth of the discontinuities (Stixrude, 1997). However, we see no evidence for this in the present datasets. Our data is consistent with compositional effects on seismic velocities and discontinuity topographies being small, or with the compositional and thermal heterogeneities having similar effects on both the shear velocity and transition zone thickness.

The maximum transition zone thickness anomaly that we observe is around $30 \mathrm{~km}$, beneath the station STKA in Australia (Figs. 9 and 10). We estimate the peak-to-peak amplitude of the global $\delta H_{\mathrm{TZ}}$ variations to be $\pm 25-30 \mathrm{~km}$ at the scale lengths of $\approx 500 \mathrm{~km}$ and larger. Ignoring effects of composition, this corresponds to thermal heterogeneity of around $\pm 200 \mathrm{~K}$. A more typical range of $\delta H_{\mathrm{TZ}}$ appears to be $\pm 15 \mathrm{~km}$ (usually, $\delta t_{\mathrm{diff}}<1 \mathrm{~s}$ ), implying $\pm 100 \mathrm{~K}$ variations of the transition zone temperature.

According to the smaller-scale subduction-zone studies, the huge thermal anomalies in the cold subducting lithosphere cause much larger changes in $d_{410}, d_{660}$, and $H_{\mathrm{TZ}}$, as should be expected (e.g. Castle and Creager, 1998). In $P \mathrm{~d} s$ measurements, smallscale topography on discontinuities manifests itself in 
large scatter, splitting, or absence of converted-wave arrivals (Van der Lee et al., 1994). Such complexity is observed at locations both near subduction zones and away from them (Chevrot et al., 1999); the regions with strong small-scale discontinuity topography are apparently distributed among areas with smoother $(\geq 500 \mathrm{~km})$ variations.

The correlation of $t_{\mathrm{diff}}$ and $\beta_{\mathrm{TZ}}$ on both regional and global scales represents evidence in support of the view that phase transformations in olivine give rise to the 410 and $660 \mathrm{~km}$ discontinuities.

\section{Acknowledgements}

We thank Alet Zielhuis for running the resolution tests for the tomographic model of Australia, Oded Aharonson for carrying out the spherical-harmonic expansion of $t_{\text {diff }}$, the Scripps and Harvard seismology groups for making their models and software available, and $\mathrm{Yu} \mathrm{Gu}$, Hitoshi Kawakatsu, and an anonymous referee for constructive reviews. The figures were prepared with GMT (Wessel and Smith, 1995). This work was supported by the David and Lucile Packard Foundation through a Fellowship awarded to R.D. van der Hilst.

\section{References}

Anderson, D.L., 1967. Phase changes in the upper mantle. Science 157, 1165-1173.

Backus, G.E., Gilbert, F., 1968. The resolving power of gross Earth data. Geophys. J. Roy. Astron. Soc. 16, 169-205.

Becker, T.W., Boschi, L., 2002. A comparison of tomographic and geodynamic mantle models. Geochem. Geophys. Geosyst. 3, Paper No. 20016 C000168.

Bernal, J.D., 1936. Geophysical discussion. Observatory 59, 265269.

Bina, C.R., Helffrich, G.R., 1994. Phase transition Clapeyron slopes and transition zone seismic discontinuity topography. J. Geophys. Res. 99, 15853-15860.

Bostock, M.G., 1996. Ps conversions from the upper mantle transition zone beneath the Canadian landmass. J. Geophys. Res. 101, 8383-8402.

Castle, J.C., Creager, K.C., 1998. Topography of the $660-\mathrm{km}$ seismic discontinuity beneath Izu-Bonin: implications for tectonic history and slab deformation. J. Geophys. Res. 103, 12511-12527.

Chaljub, E., Tarantola, A., 1997. Sensitivity of SS precursors to topography on the upper mantle 660-km discontinuity. Geophys. Res. Lett. 24, 2613-2616.
Chevrot, S., Vinnik, L., Montagner, J.-P., 1999. Global scale analysis of the mantle $P \mathrm{~d} s$ phases. J. Geophys. Res. 104, 20203-20219.

Collier, J., Helffrich, G., 1997. Topography of the "410" and "660" $\mathrm{km}$ seismic discontinuities in the Izu-Bonin subduction zone. Geophys. Res. Lett. 24, 1535-1538.

Dueker, K.G., Sheehan, A.F., 1997. Mantle discontinuity structure from midpoint stacks of converted $P$ to $S$ waves across the Yellowstone hotspot track. J. Geophys. Res. 102, 8313-8327.

Dziewonski, A.M., Anderson, D.L., 1981. Preliminary reference Earth model. Phys. Earth Planet. Inter. 25, 297-356.

Efron, B., Tibshirani, R., 1991. Statistical data analysis in the computer age. Science 253, 390-395.

Ekström, G., Dziewonski, A.M., 1998. The unique anisotropy of the Pacific upper mantle. Nature 394, 168-172.

Flanagan, M.P., Shearer, P.M., 1998. Global mapping of topography on transition zone velocity discontinuities by stacking SS precursors. J. Geophys. Res. 103, 2673-2692.

Goes, S., Govers, R., Vacher, P., 2000. Shallow mantle temperatures under Europe from $P$ and $S$ wave tomography. J. Geophys. Res. 105, 11153-11169.

Gössler, J., Kind, R., 1996. Seismic evidence for very deep roots of continents. Earth Planet. Sci. Lett. 138, 1-13.

Grand, S.P., van der Hilst, R.D., Widiyantoro, S., 1997. Global seismic tomography; a snapshot of convection in the Earth. GSA Today 7, 1-7.

Gu, Y., Dziewonski, A.M., Agee, C.B., 1998. Global de-correlation of the topography of transition zone discontinuities. Earth Planet. Sci. Lett. 157, 57-67.

Gurrola, H., Minster, J.B., 1998. Thickness estimates of the upper-mantle transition zone from bootstrapped velocity spectrum stacks of receiver functions. Geophys. J. Int. 133, 31-43.

Helffrich, G., 2000. Topography of the transition zone seismic discontinuities. Rev. Geophys. 38, 141-158.

Hung, S.-H., Dahlen, F.A., Nolet, G., 2000. Fréchet kernels for finite-frequency traveltimes. Part II. Examples. Geophys. J. Int. 141, 175-203.

Irifune, T., Nishiyama, N., Kuroda, K., Inoue, T., Isshiki, M., Utsumi, W., Funakoshi, K., Urakawa, S., Uchida, T., Katsura, T., Ohtaka, O., 1998. The postspinel phase boundary in $\mathrm{Mg}_{2} \mathrm{SiO}_{4}$ determined by in situ X-ray diffraction. Science 279, 16981700 .

Ito, E., Takahashi, E., 1989. Postspinel transformations in the system $\mathrm{Mg}_{2} \mathrm{SiO}_{4}-\mathrm{Fe}_{2} \mathrm{SiO}_{4}$ and some geophysical implications. J. Geophys. Res. 94, 10646-10673.

Katsura, T., Ito, E., 1989. The system $\mathrm{Mg}_{2} \mathrm{SiO}_{4}-\mathrm{Fe}_{2} \mathrm{SiO}_{4}$ at high pressures and temperatures: precise determination of stabilities of olivine, modified spinel, and spinel. J. Geophys. Res. 94, 15663-15670.

Kennett, B.L.N., Engdahl, E.R., 1991. Travel times for global earthquake location and phase identification. Geophys. J. Int. 105, 429-465.

Karato, S., 1993. Importance of anelasticity in the interpretation of seismic tomography. Geophys. Res. Lett. 20, 1623-1626.

Lebedev, S., Nolet, G., 2000. Tomographic constraints on the structure and evolution of the SE Asian and W Pacific upper mantle. EOS Trans. AGU 81, S322. 
Li, X., Kind, R., Priestley, K., Sobolev, S.V., Tilmann, F., Yuan, X., Weber, M., 2000. Mapping the Hawaiian plume conduit with converted seismic waves. Nature 405, 938-941.

Masters, , G, , Johnson, S., Laske, G., Bolton, H., 1996. A shear-velocity model of the mantle. Phil. Trans. R. Soc. L. 354, $1385-1410$.

Navrotsky, A., 1980. Lower mantle phase transitions may generally have negative pressure-temperature slopes. Geophys. Res. Lett. 7, 709-711.

Neele, F., de Regt, H., VanDecar, J., 1997. Gross errors in upper-mantle discontinuity topography from underside reflection data. Geophys. J. Int. 129, 194-204.

Nolet, G., 1990. Partitioned waveform inversion and twodimensional structure under the Network of Autonomously Recording Seismographs. J. Geophys. Res. 95, 8499-8512.

Revenaugh, J., Jordan, T.H., 1991. Mantle layering from ScS reverberations 2. The transition zone. J. Geophys. Res. 96, 19763-19780.

Ringwood, A.E., 1969. Phase transformations in the mantle. Earth Planet. Sci. Lett. 5, 401-412.

Shearer, P.M., Flanagan, M.P., Hedlin, M.A.H., 1999. Experiments in migration processing of SS precursor data to image upper mantle discontinuity structure. J. Geophys. Res. 104, 72297242 .

Shearer, P.M., 2000. Upper mantle seismic discontinuities. In: Karato, S., Forte, A.M., Liebermann, R.C., Masters, G., Stixrude, L. (Eds.), Earth's Deep Interior: Mineral Physics and Tomography From the Atomic to the Global Scale. AGU, Geophys. Monograph, 117, 115-131.

Shim, S.-H, Duffy, T.S., Shen, G., 2001. The post-spinel transformation in $\mathrm{Mg}_{2} \mathrm{SiO}_{4}$ and its relation to the $660-\mathrm{km}$ seismic discontinuity. Nature 411, 571-574.

Simons, F.J., Zielhuis, A., van der Hilst, R.D., 1999. The deep structure of the Australian continent from surface-wave tomography. Lithosphere 48, 17-43.

Stixrude, L., 1997. Structure and sharpness of phase transitions and mantle discontinuities. J. Geophys. Res. 102, 14835-14852.
Su, W.-J., Woodward, R.L., Dziewonski, A.M., 1994. Degree 12 model of shear velocity heterogeneity in the mantle. J. Geophys. Res. 99, 6945-6980.

Suito, K., 1977. Phase relations of pure $\mathrm{Mg}_{2} \mathrm{SiO}_{4}$ up to 200 kilobars. In: Manghnani, M., Akimoto, S. (Eds.), High-Pressure Research: Applications in Geophysics. Academic Press, San Diego, CA, 255-266.

Van der Hilst, R.D., Kennett, B., Christie, D., Grant, J., 1994. Project SKIPPY explores the lithosphere and mantle beneath Australia. EOS Trans. AGU 75, 177, 180-181.

Van der Hilst, R.D., Widiyantoro, S., Engdahl, R.E., 1997. Evidence for deep mantle circulation from global tomography. Nature 386, 578-584.

Van der Lee, S., Paulssen, H., Nolet, G., 1994. Variability of $P 660$ s phases as a consequence of topography of the $660-\mathrm{km}$ discontinuity. Phys. Earth Planet. Inter. 86, 147-164.

Vidale, J.E., Benz, H.M., 1992. Upper-mantle seismic discontinuities and the thermal structure of subduction zones. Nature 356, 678-683.

Vinnik, L.P., 1977. Detection of waves converted from $P$ to $S V$ in the mantle. Phys. Earth Planet. Inter. 15, 39-45.

Weidner, D.J., Wang, Y., 2000. Phase transformations: implications for mantle structure. In: Karato, S., Forte, A.M., Liebermann, R.C., Masters, G., Stixrude, L. (Eds.), Earth's Deep Interior: Mineral Physics and Tomography From the Atomic to the Global Scale. AGU, Geophys. Monograph, 117, 215-235.

Wessel, P., Smith, W.H.F., 1995. New version of the generic mapping tools released. EOS Trans. AGU 76, 329.

Wicks, C.W., Richards, M.A., 1993. A detailed map of the 660-kilometer discontinuity beneath the Izu-Bonin subduction zone. Science 261, 1424-1427.

Zhao, L., Jordan, T.H., Chapman, C.H., 2000. Three-dimensional Fréchet differential kernels for seismic delay times. Geophys. J. Int. 141, 558-576.

Zielhuis, A., van der Hilst, R.D., 1996. Upper-mantle shear velocity beneath eastern Australia from inversion of waveforms from SKIPPY portable arrays. Geophys. J. Int. 127, 1-16. 